\title{
Construction of a Minimal Deterministic Finite Automaton from a Regular Expression
}

\author{
Sanjay Bhargava \\ Department of Computer Science \\ Banasthali University \\ C-62, Sarojini Marg, C-Scheme, Jaipur - 302001
}

\author{
G. N. Purohit \\ Centre for Mathematical Science \\ Banasthali University \\ Banasthali, Rajasthan - 304022
}

\begin{abstract}
This paper describes a method for constructing a minimal deterministic finite automaton (DFA) from a regular expression. It is based on a set of graph grammar rules for combining many graphs (DFA) to obtain another desired graph (DFA). The graph grammar rules are presented in the form of a parsing algorithm that converts a regular expression $\mathrm{R}$ into a minimal deterministic finite automaton $\mathrm{M}$ such that the language accepted by DFA M is same as the language described by regular expression $\mathrm{R}$.

The proposed algorithm removes the dependency over the necessity of lengthy chain of conversion, that is, regular expression $\rightarrow$ NFA with $\varepsilon$-transitions $\rightarrow$ NFA without $\varepsilon$ transitions $\rightarrow$ DFA $\rightarrow$ minimal DFA. Therefore the main advantage of our minimal DFA construction algorithm is its minimal intermediate memory requirements and hence, the reduced time complexity. The proposed algorithm converts a regular expression of size $\mathrm{n}$ in to its minimal equivalent DFA in $\mathrm{O}\left(\mathrm{n} \cdot \log _{2} \mathrm{n}\right)$ time. In addition to the above, the time complexity is further shortened to $\mathrm{O}\left(\mathrm{n} \cdot \log _{\mathrm{e}} \mathrm{n}\right)$ for $\mathrm{n} \geq 75$.
\end{abstract}

\section{General Terms}

Algorithms, Complexity of Algorithm, Regular Expression, Deterministic Finite Automata (DFA), Minimal DFA.

\section{Keywords}

Alphabet, Automaton Construction, Combined State, Union, Concatenation, Kleene Closure, Minimization, Transition.

\section{INTRODUCTION AND BACKGROUND}

Regular expressions and finite automata are two dissimilar representations for regular languages: regular expressions on one hand generate regular languages while on the other hand finite automata accept regular languages. It is well known that each regular expression can be transformed into a nondeterministic finite automaton (NFA) with or without $\varepsilon$ transitions, and finally this NFA can be converted into a DFA. In the literature related to the conversion problem, it has been found that there exist many different algorithmic approaches for converting a regular expression into some variant of a finite automaton; Watson [34] enumerated various algorithmic approaches for the conversion problem. Algorithmic approaches to convert a regular expression into some variant of a finite automaton include:

- The algorithms to convert regular expression into NFA with or without $\varepsilon$-transitions (see, e.g. [1], [5], [6], [12], [13], [16], [18], [20], [21], [23], [28], [33], [36] and [37]) and

- The algorithms to convert regular expression into DFA using intermediate NFAs (as in various studies like [2], [3],
[4], [9], [10], [15], [19], [24], [25], [29], [30], [31], [32] and [35]).

Daciuk et al. [11] discussed a parsing algorithm to convert a set of strings into a minimal, deterministic, acyclic finite-state automaton. Carrasco and Forcada [8] presented another algorithm to modify any minimal finite-state automaton so that a string is added to or removed from the language accepted by it. Recently, Carrasco et al. [7] presented another algorithm that allowed the incremental addition or removal of unranked order trees to a minimal frontier-to-root deterministic finite-state tree automaton. All the above studies had limitations as they represented only a finite set of strings.

The traditional methods, discussed above, to convert a regular expression R into a minimal DFA M consist of four phases: (i) to convert $\mathrm{R}$ into a non-deterministic finite automaton (NFA) with $\varepsilon$-transitions, (ii) to convert the above NFA into an NFA without $\varepsilon$-transitions, (iii) to convert this NFA (without $\varepsilon$ transitions) into a DFA, and finally (iv) to minimize this DFA. This paper presents a parsing algorithm Construct which converts a regular expression (finite as well as infinite set of strings) into a minimal DFA using the following two phases, recursively.

(i) Constructing a DFA (for $\varepsilon / \phi /$ a single alphabet symbol / kleene closure of a DFA / union of two DFA / concatenation of two DFA) by applying the rules for automaton construction and joining operations of DFA (Cohen [10]), and

(ii) Minimizing the obtained DFA (Hopcroft and Ullman [19]).

In the proposed algorithm, parsing is performed by (i) obtaining the information from regular expression in a precise manner and then (ii) converting this information into DFA using the graph grammar rules defined for this conversion. Following Johnson et al. [22], Möhring [27] and Mayr et al. [26], we have prescribed a set of graph grammar rules for minimization, union, concatenation, and kleene closure operations over DFA and our parsing algorithm works as a genuine folder containing all these rules. Throughout the conversion process, graph operations needed to join DFA take place using an appropriate graph grammar rule from this folder.

The contents of this paper are arranged as follows.

Section 2 describes the proposed implementation procedure, followed by the equivalent algorithm to convert a regular expression into a minimal DFA in the next section. This section also depicts the instances of our algorithm's implementation initially by graphs and followed by tables. Finally, this section 
ends with an evaluation of the algorithm. Last Section 4 deals with the conclusions of the present research paper.

\section{IMPLEMENTATION PROCEDURE}

Following Brzozowski and Cohen [6] and Antimirov [1], the proposed algorithm Construct first constructs a minimal DFA (graph) for the deepest positioned element of the given regular expression. In the next step, Construct combines this DFA with the DFA based on the surrounding part of deepest element's position, to obtain another minimal DFA. The process of combining DFA is continued till the entire regular expression is converted into the resultant DFA. The implementation procedure is described in detail as follows.

Construct first stores the given regular expression $\mathrm{R}$ as (R) in an array $\mathrm{X}$. Therefore the start and end markers of $\mathrm{R}$ are '(' and ')' respectively. Then, following Berry and Sethi [3], Construct obtains the address of innermost parenthesis string say $\mathrm{R}_{1}$ of $\mathrm{R}$. Construct then scans $\mathrm{R}_{1}$ for some ${ }^{*} \forall \mathrm{x} \in \Sigma \cup$ $\left\{\varepsilon, \phi, \mathrm{M}_{\mathrm{z}}\right.$ such that $\mathrm{z} \geq 1\left(M_{z}\right.$ will not exist for $R_{1}$ and can exist only for $R_{2}$ onwards) $\}$, and if any such $\mathrm{x}^{*}$ exists, Construct constructs the minimal DFA for those entire ${ }^{*}$ Construct first constructs an intermediate DFA say I for $x$, and then for $x^{*}$ it obtains the kleene closure DFA of I, and finally it stores the so obtained DFA in some $L_{i}$ ), and replaces all $\mathrm{x}^{*}$ by their equivalent minimal DFA name $\mathrm{L}_{\mathrm{i}}$ for $\mathrm{i}$ $\geq 1$ in $R_{1}$. Construct also stores all those $L_{i}$ 's in XL. Thereby, in the string $\mathrm{R}_{1}$ all $\mathrm{x}^{*}$ are replaced by some $\mathrm{L}_{\mathrm{i}}$ for $\mathrm{i}$ $\geq 1$.

Construct again scans $\mathrm{R}_{1}$ for some string $\mathrm{s} \forall \mathrm{s} \in \Sigma^{*} \cup\{\phi\} \cup$ $\left\{\mathrm{L}_{\mathrm{i}}, \mathrm{M}_{\mathrm{z}} \text { for } \mathrm{i}, \mathrm{z} \geq 1\right\}^{*}$, and if any such s exists, Construct constructs the minimal DFA for all those $\mathrm{s}$ recursively (Construct first constructs a DFA $N_{j}$ for the $1^{\text {st }}$ character of string $s$; then if $s$ contains another character, Construct concatenates $N_{j}$ by the DFA of that character and stores the resultant minimal DFA back in $N_{j}$, and this process continues till the whole $s$ is consumed) and replaces all $\mathrm{s}$ by their equivalent minimal DFA name $\mathrm{N}_{\mathrm{j}}$ for $\mathrm{j} \geq 1$. Construct also stores all those $\mathrm{N}_{\mathrm{j}}$ 's in $\mathrm{XN}$. Hence, in the string $\mathrm{R}_{1}$, all $\mathrm{s}$ are replaced by some $\mathrm{N}_{\mathrm{j}}$ for $\mathrm{j} \geq 1$.

$\mathrm{R}_{1}$ is again scanned for a '+' operator. If a '+' does not exist, the only $\mathrm{N}_{\mathrm{j}}$ value in $\mathrm{R}_{1}$ is stored as $\mathrm{M}_{1}$. However in the presence of a ' + ' operator, Construct assumes that it is between $x$ and $y \forall x, y \in\left\{\mathrm{N}_{\mathrm{j}}\right.$ for $\left.\mathrm{j} \geq 1\right\}$. Construct stores the left side operand of ' + ' as $M_{1}$ and joins this $M_{1}$ to the right side operand of ' + ' using union operation, and stores the result (minimal DFA) back in $\mathrm{M}_{1}$; then Construct again searches for the next ' + ' operator in $\mathrm{R}_{1}$, and if found Construct again joins $\mathrm{M}_{1}$ to the right side operand of ' + ' using union operation, and stores the result (minimal DFA) back in $\mathrm{M}_{1}$; Construct continues till the entire string $\mathrm{R}_{1}$ is replaced by $\mathrm{M}_{1}$. Construct also stores $\mathrm{M}_{1}$ in XM.

Construct then replaces the entire $\left(\mathrm{R}_{1}\right)$ ("("), followed by string $R_{l}$, followed by ")") by $\mathrm{M}_{1}$. As the innermost left and right parentheses are removed, Construct has, possibly, a new innermost parenthesis (the next higher parenthesis after the parenthesis for $R_{1}$ ). Let the innermost parenthesis string be $\mathrm{R}_{2}$. Construct performs the same operation with $\mathrm{R}_{2}$ as it had done with $\mathrm{R}_{1}$ to get the next string $\mathrm{R}_{3}$. Continuing like this, Construct will replace the entire regular expression $\mathrm{R}$ by an equivalent minimal DFA name $M_{z}$ for $z \geq 1$. Finally, the last $\mathrm{M}_{\mathrm{z}}$ is printed and stored as the output $\mathrm{M}$.

In the implementation procedure, inside the regular expression Construct performed all the replacement operations by replacing strings $\mathrm{L}_{\mathrm{i}}, \mathrm{N}_{\mathrm{j}}$, or $\mathrm{M}_{\mathrm{z}}$ (for $i, j, z \geq 1$ ) into the regular expression (as in Ben-David et al. [2]). The exact values of these $L_{i}, N_{j}$, and $M_{z}$ were stored on XL, XN, and XM respectively. Whenever Construct replaced anyone of $\mathrm{L}_{\mathrm{i}}, \mathrm{N}_{\mathrm{j}}$, or $\mathrm{M}_{\mathrm{z}}$ into the regular expression, the corresponding value of $\mathrm{L}_{\mathrm{i}}, \mathrm{N}_{\mathrm{j}}$, or $\mathrm{M}_{\mathrm{z}}$ was either appended to the sets $\mathrm{XL}, \mathrm{XN}$, or $\mathrm{XM}$ respectively (if $L_{i}, N_{j}$, or $M_{z}$ was $n e w$ ) or was updated in $\mathrm{XL}, \mathrm{XN}$, or XM respectively (if $L_{i}$, $N_{j}$, or $M_{z}$ was already existing). Similarly if Construct read anyone of $\mathrm{L}_{\mathrm{i}}, \mathrm{N}_{\mathrm{j}}$, or $\mathrm{M}_{\mathrm{z}}$ inside a regular expression, the corresponding value of $\mathrm{L}_{\mathrm{i}}, \mathrm{N}_{\mathrm{j}}$, or $\mathrm{M}_{\mathrm{z}}$ was extracted from XL, $\mathrm{XN}$, or $\mathrm{XM}$ respectively, some join operation (union, concatenation, or kleene closure) was performed over them, and the resultant value was stored back in $\mathrm{XL}, \mathrm{XN}$, or $\mathrm{XM}$ respectively along with storing the same string name into the regular expression (For example if $L_{3}$ was DFA for $a^{*}$, then ' $L_{3}$ ' was over-written in place of $a^{*}$ in regular expression and the exact value of $L_{3}$ was also stored in XL. Similarly, if we wanted to concatenate $N_{3}$ followed by DFA for symbol 1 , we first extracted the current value of $N_{3}$ from $X N$, concatenated it with the DFA for symbol 1, stored the resultant DFA back as $N_{3}$, stored the value of $N_{3}$ in $X N$ at the previous place of $N_{3}$, and rewrote ' $N_{3} l$ ' as ' $N_{3}$ ' inside the regular expression.).

Following Rytter [28], Construct used a high-speed processor that performed all the graph operations in almost insignificant time. Whenever any of the graph grammar function (Symbol, Union, Concat, Star, and Min) was called inside the algorithm, the processor was activated and after activation it performed the following sequence of operations in a constant and insignificant time:

(i) It obtained the information from array $\mathrm{X}$ and used the function that activated it.

(ii) It executed the associated function (the function that activated the processor) with the input, as received from $X$. If this input was an already stored string name $\left(\mathrm{L}_{\mathrm{i}}, \mathrm{N}_{\mathrm{j}}\right.$, or $\mathrm{M}_{\mathrm{z}}$ ), then the processor extracted the value of that string name from $\mathrm{XL}, \mathrm{XN}$, or XM and used that extracted value as input, otherwise the processor used the same read input.

(iii) It stored the output $\left(\mathrm{L}_{\mathrm{i}}, \mathrm{N}_{\mathrm{j}}\right.$, or $\left.\mathrm{M}_{\mathrm{z}}\right)$ of the associated function by overwriting that output name $\left(\mathrm{L}_{\mathrm{i}}, \mathrm{N}_{\mathrm{j}}\right.$, or $\left.\mathrm{M}_{\mathrm{z}}\right)$ in array $\mathrm{X}$ at the place from where the input was taken. It also stored the full description of $\mathrm{L}_{\mathrm{i}}, \mathrm{N}_{\mathrm{j}}$, or $\mathrm{M}_{\mathrm{z}}$ in $\mathrm{XL}$, $\mathrm{XN}$, or XM respectively.

\section{ALGORITHM}

Algorithm Construct takes a regular expression $\mathrm{R}$ and a finite set of alphabet symbols $\Sigma$ as input and prints the minimal DFA $M$ as output such that $L(M)=L(R)$. Figure 1 shows the algorithm Construct.

Algorithm Construct

Input: a regular expression $\mathrm{R}$ and a set $\Sigma$ of alphabet symbols.

Output: a minimal DFA M such that $\mathrm{L}(\mathrm{M})=\mathrm{L}(\mathrm{R})$. 
type automata $=(\mathrm{Q}, \Sigma, \delta, \mathrm{Q}[1], \mathrm{F})$;

M : automata;

begin

$\mathrm{M} \leftarrow$ Converter $(\mathrm{R}, \Sigma)$;

[M stores the output sent by function Converter] print M;

[output $M$ is printed]

end

Figure 1. Algorithm Construct to print the minimal DFA equivalent to a regular expression.

Algorithm Construct calls the function Converter, which maintains all the replace operations in array $\mathrm{X}$ (array $X$ contains $R$ ) for converting $\mathrm{R}$ into a minimal DFA M. Figure 2 shows the function Converter.

Function Converter $(\mathrm{R}, \Sigma)$

begin

if $\mathrm{R}=\phi \mathrm{OR} \mathrm{R}=$ ' $\varepsilon$ ' OR length $(\mathrm{R})=1$ then

begin

return Symbol(R); [function Symbol returns min. DFA for $\phi / \varepsilon$ / reg. exp. of length 1]

end;

endif;

int $\mathrm{n}, \mathrm{n}_{1}, \mathrm{i}, \mathrm{j}, \mathrm{z}$, inner, outer, left_paren, right_paren, position_star, inter, count;

$\mathrm{n} \leftarrow$ length $(\mathrm{R})$

$\mathrm{X}:$ array [1..n+2] of $\Sigma \cup\left\{(),, \#, \mathrm{~L}_{\mathrm{i}}, \mathrm{N}_{\mathrm{j}}, \mathrm{M}_{\mathrm{z}}\right.$ for $\left.\mathrm{i}, \mathrm{j}, \mathrm{z} \geq 1\right\}$;

$\mathrm{z} \leftarrow 1 ; \mathrm{X}[1] \leftarrow$ '(';

Store $R$ in array $X$ from $2^{\text {nd }}$ to $(n+1)^{\text {th }}$ position; $X[n+2] \leftarrow$ ')';

$\mathrm{n}_{1} \leftarrow \mathrm{n}+2$;

$10 \mathrm{i}, \mathrm{j} \leftarrow 1$;

find the innermost bracket in X;

inner $\leftarrow$ in such that $X[i n]$ contains the left parenthesis of innermost bracket;

outer $\leftarrow$ out such that $\mathrm{X}$ [out] contains the right parenthesis of innermost bracket;

left_paren $\leftarrow$ inner; right_paren $\leftarrow$ outer;

scan $\mathrm{X}$ from $\mathrm{X}$ [inner] to $\mathrm{X}$ [outer] for all $\mathrm{x}^{*}$ where $\mathrm{x} \in \Sigma \cup\{\varepsilon, \phi$, $\mathrm{M}_{\mathrm{z}}$ for $\mathrm{z} \geq 1$ \}

if $\mathrm{x}^{*}$ found then for every $\mathrm{x}^{*}$ such that $\mathrm{X}[$ position_star $]=\mathrm{x}$

if X[position_star] $=\mathrm{M}_{\mathrm{z}}$ then $\mathrm{L}_{\mathrm{i}} \leftarrow \operatorname{Min}(\operatorname{Star}(\mathrm{X}[$ position_star $]))$

else $\mathrm{L}_{\mathrm{i}} \leftarrow \operatorname{Min}(\operatorname{Star}(\operatorname{Symbol}(\mathrm{X}[$ position_star] $)))$

endif;

$\mathrm{X}\left[\right.$ position_star] $\leftarrow \mathrm{L}_{\mathrm{i}} ; \quad$ [X]position_star] stores the automata name for $x^{*}$ ]

store $\mathrm{L}_{\mathrm{i}}$ in $\mathrm{XL}$;

[automata $L_{i}$ for $x^{*}$ is stored in $\mathrm{XL}$ ]

$\mathrm{i} \leftarrow \mathrm{i}+1$;

shift the values of $\mathrm{X}\left[\right.$ position_star+2] to $\mathrm{X}\left[\mathrm{n}_{1}\right]$ to 1 position left in $\mathrm{X}$;

$\mathrm{X}\left[\mathrm{n}_{1}\right] \leftarrow$ '\#'; outer $\leftarrow$ outer -1 ;

endif;

if no ${ }^{*}$ found then exit endif;

endscan;

inter $\leftarrow$ inner;

15 scan $\mathrm{X}$ from $\mathrm{X}$ [inter] to $\mathrm{X}$ [outer]

count $\leftarrow$ inter +1 ;

if $\mathrm{X}$ [count] $\in \Sigma \cup \varepsilon \cup \phi$ then $\mathrm{N}_{\mathrm{j}} \leftarrow \operatorname{Symbol}\left(\mathrm{X}\right.$ [count]) else $\mathrm{N}_{\mathrm{j}} \leftarrow$ $\mathrm{X}$ [count]

endif;

$\mathrm{X}[$ count $] \leftarrow \mathrm{N}_{\mathrm{j}}$;

store $\mathrm{N}_{\mathrm{j}}$ in $\mathrm{XN}$;

$\left[X[\right.$ count $]$ stores the automata name $\left.N_{j}\right]$ [automata $\mathrm{N}_{\mathrm{j}}$ is stored in $\mathrm{XN}$ ] count $\leftarrow$ count +1

20 if $\mathrm{X}$ [count] $\in \Sigma \cup \varepsilon \cup \phi$ then

$\mathrm{N}_{\mathrm{j}} \leftarrow \operatorname{Min}\left(\operatorname{Concat}\left(\mathrm{N}_{\mathrm{j}}, \operatorname{Symbol}(\mathrm{X}[\operatorname{count}])\right)\right)$;

$\mathrm{X}$ [count-1] $\leftarrow \mathrm{N}_{\mathrm{j}}$; $\quad$ store $\mathrm{N}_{\mathrm{j}}$ in $\mathrm{XN}$;

shift the values of $X[$ count +1$]$ to $X\left[n_{1}\right]$ to 1 position left;

$\mathrm{X}\left[\mathrm{n}_{1}\right] \leftarrow$ '\#'; outer $\leftarrow$ outer-1; go to 20 ;

endif;

if $X$ count $] \in\left\{\mathrm{L}_{\mathrm{i}}, \mathrm{M}_{\mathrm{z}}\right.$ for $\left.\mathrm{i}, \mathrm{z} \geq 1\right\}$ then

$\mathrm{N}_{\mathrm{j}} \leftarrow \operatorname{Min}\left(\operatorname{Concat}\left(\mathrm{N}_{\mathrm{j}}, \mathrm{X}[\right.\right.$ count $\left.\left.]\right)\right)$;

$\mathrm{X}$ [count-1] $\leftarrow \mathrm{N}_{\mathrm{j}}$; store $\mathrm{N}_{\mathrm{j}}$ in $\mathrm{XN}$;

shift the values of $X[$ count +1$]$ to $X\left[n_{1}\right]$ to 1 position left;

$\mathrm{X}\left[\mathrm{n}_{1}\right] \leftarrow$ '\#'; outer $\leftarrow$ outer- 1 ; go to 20 ;

endif;

if $X[$ count $]=$ ' + ' then

$\mathrm{j} \leftarrow \mathrm{j}+1$; inter $\leftarrow$ count; go to 15 ;

endif;

if $X[$ count $]=$ ')' then

$\mathrm{j} \leftarrow \mathrm{j}+1$;

endif;

endscan;

scan $\mathrm{X}$ from $\mathrm{X}$ [inner] to $\mathrm{X}$ [outer]

$\mathrm{M}_{\mathrm{z}} \leftarrow \mathrm{X}[$ inner +1$] ; \quad$ [Some $\mathbf{N}_{\mathrm{j}}$ at $\mathrm{X}$ [inner+1] is stored in name $\left.M_{z}\right]$

$\mathrm{X}$ [inner+1] $\leftarrow \mathrm{M}_{\mathrm{z}}$; $\left[\mathbf{X}\left[\right.\right.$ inner+1] stores the automata name $\left.\mathbf{M}_{\mathbf{Z}}\right]$ store $\mathrm{M}_{\mathrm{z}}$ in $\mathrm{XM}$;

30 if $\mathrm{X}[$ inner +2$]={ }^{\prime}+$ ' then

[automata $M_{z}$ is stored in $\mathrm{XM}$ ]

$\mathrm{M}_{\mathrm{z}} \leftarrow \operatorname{Min}\left(\operatorname{Union}\left(\mathrm{M}_{\mathrm{z}}, \mathrm{X}[\right.\right.$ inner+3] $\left.)\right)$;

$\mathrm{X}\left[\right.$ inner+1] $\leftarrow \mathrm{M}_{\mathrm{z}}$;

store $\mathrm{M}_{\mathrm{z}}$ in $\mathrm{XM}$;

shift the values of $X[$ inner +4$]$ to $X\left[n_{1}\right]$ to 2 positions left;

$\mathrm{X}\left[\mathrm{n}_{1}-1\right], \mathrm{X}\left[\mathrm{n}_{1}\right] \leftarrow$ '\#'; outer $\leftarrow$ outer- 2 ;

go to 30 ;

endif;

if $X[$ inner +2$]=$ ')' then endif;

endscan;

$\mathrm{z} \leftarrow \mathrm{z}+1$

shift the values of $X\left[\right.$ inner+1] to $X\left[n_{1}\right]$ to 1 position left;

shift the values of $X\left[\right.$ outer] to $X\left[n_{1}\right]$ to 1 position left;

replace '\#' from $X\left[n_{1}+1\right.$-(right_paren-left_paren) $]$ to $X\left[n_{1}\right]$;

$\mathrm{n}_{1} \leftarrow \mathrm{n}_{1}-$ (right paren-left paren);

if $\mathrm{n}_{1}=1$ then return $\mathrm{X}\left[\mathrm{n}_{1}\right]$ else go to 10 endif;

[value of $X\left[n_{1}\right]$ i.e. $M_{z}$ is returned]

end function;

Figure 2. Function Converter to convert a regular expression $\mathbf{R}$ into minimal DFA.

Function Converter stores regular expression $\mathrm{R}$ in an array $\mathrm{X}$ from $2^{\text {nd }}$ to $(\mathrm{n}+1)^{\text {th }}$ position, where $\mathrm{n}=$ length $(\mathrm{R}) . \mathrm{X}[1]$ and $\mathrm{X}[\mathrm{n}+2]$ are initialized as '(' and ')' respectively. Then Converter constructs the DFA using the following three phases recursively.

(i) During the first phase, Converter captures the innermost parenthesis string, say $\mathrm{R}_{1}$. Inside $\mathrm{R}_{1}$, it replaces all $\mathrm{x}^{*}$ ( $x$ can be a symbol of $\Sigma$, or $\phi$, or ' $\varepsilon$ ', or an already existing DFA name $M_{z}$ ) by their equivalent minimal DFA name $\mathrm{L}_{\mathrm{i}}$ in $\mathrm{R}_{1}$ and also stores these $\mathrm{L}_{\mathrm{i}}$ 's in XL.

(ii) During the second phase, Converter again scans $R_{1}$ from left to right in search of some $\mathrm{s} \forall \mathrm{s} \in \Sigma^{*} \cup\{\phi\} \cup$ 
$\left\{L_{i}, M_{z} \text { for } i, z \geq 1\right\}^{*}$, and replaces all such $s$ by their equivalent minimal DFA name $\mathrm{N}_{\mathrm{j}}$ in $\mathrm{R}_{1}$ and also stores $\mathrm{N}_{\mathrm{j}}$ 's in $\mathrm{XN}$.

(iii) During the third phase, Converter again scans $R_{1}$ for ' + ' operators, and using 'union operation of DFA' it replaces the whole string $R_{1}$ by an equivalent DFA name $\mathrm{M}_{1}$ and also stores $\mathrm{M}_{1}$ in XM.

So, after the first recursion, the entire string $R_{1}$ is converted into some $M_{1}$. Then Converter replaces $\left(R_{1}\right)$ by $M_{1}$ in array $X$. It again scans $X$ for an innermost parenthesis string, say $R_{2}$. Now, Converter deals with $R_{2}$ in exactly the same way as it converted $R_{1}$ into $M_{1}$, to get $M_{2}$. This process continues until Converter is unable to find an innermost parenthesis, at which time it comes out from the recursive process, and sends the last DFA $\mathrm{M}_{\mathrm{z}}$ to the calling algorithm. Function Converter makes use of some other functions depicting graph grammar rules for various graph operations. These functions are Shiftleft, Symbol, Union, Concat, and Min. Figure 3 shows the function Shiftleft.

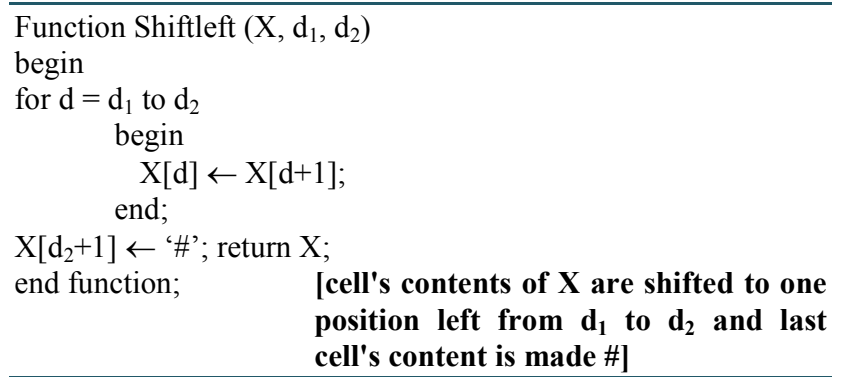
Figure 3. Function Shiftleft.

Function Shiftleft shifts the contents of $X$ to one position left, starting from $\mathrm{d}_{1}$, and also places a '\#' sign to the last cell of X. Figure 4 shows the function Symbol.

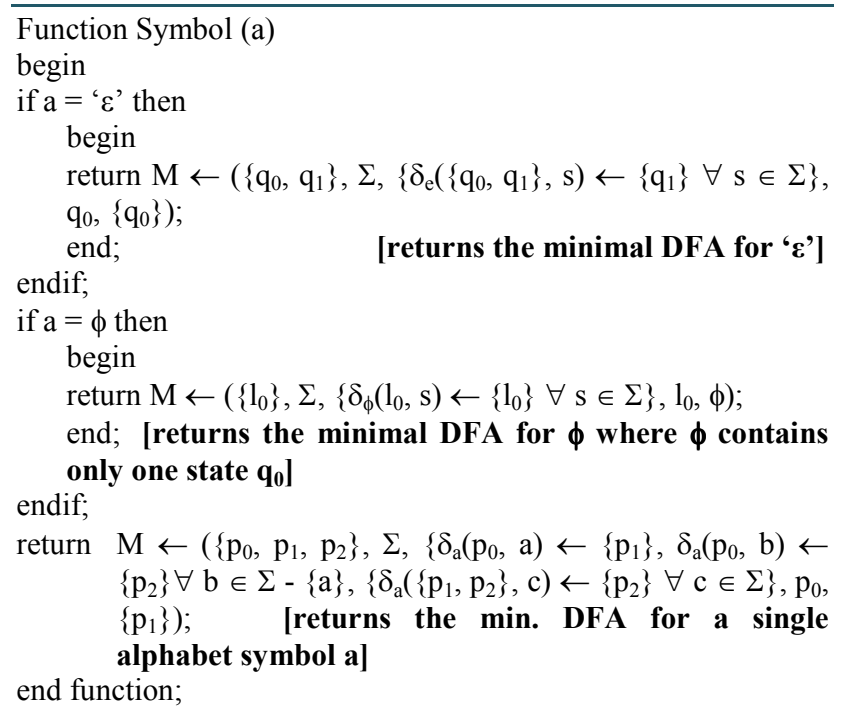

\section{Figure 4. Function Symbol obtaining min. DFA for ' $\phi$ ' or ' $\varepsilon$ ' or alphabet symbol of length 1 .}

Function Symbol converts $\varepsilon$ into a minimal DFA; the minimal DFA contains two states $\mathrm{q}_{0}$ and $\mathrm{q}_{1}$ out of which $\mathrm{q}_{0}$, the start state, is the only final state and $\mathrm{q}_{1}$ is a non-final state. There is no transition from $\mathrm{q}_{0}$ enters back to $\mathrm{q}_{0}$, and all the transitions from $\mathrm{q}_{0}$ and $\mathrm{q}_{1}$, for all alphabet symbols, enter to state $\mathrm{q}_{1}$.

Function Symbol also converts $\phi$ into a minimal DFA; the minimal DFA contains only one state $1_{0} .1_{0}$ is the start state and is also a non-final state, and all the transitions from $1_{0}$, for all alphabet symbols, enter back to state $1_{0}$.

Function Symbol also converts an alphabet symbol 'a' into a minimal DFA; the minimal DFA contains three states $\mathrm{p}_{0}, \mathrm{p}_{1}$, and $\mathrm{p}_{2}$ out of which $\mathrm{p}_{0}$ is the start state and $\mathrm{p}_{1}$ is the only final state. There is a transition that enters from $p_{0}$ to $p_{1}$ on the alphabet symbol 'a', and all other possible transitions from all the states enter to $p_{2}$ which is a non-final state. Figure 5 shows the function Union.

Function Union $\left(\mathrm{M}_{\mathrm{l}}\left(\mathrm{Q}_{\mathrm{l}}, \Sigma, \delta_{\mathrm{l}}, \mathrm{l}_{0}, \mathrm{~F}_{\mathrm{l}}\right), \mathrm{M}_{\mathrm{r}}\left(\mathrm{Q}_{\mathrm{r}}, \Sigma, \delta_{\mathrm{r}}, \mathrm{m}_{0}, \mathrm{~F}_{\mathrm{r}}\right)\right)$

begin

1_length $\leftarrow$ cardinality $\left(\mathrm{Q}_{1}\right)$; r_length $\leftarrow$ cardinality $\left(\mathrm{Q}_{\mathrm{r}}\right)$;

rename the states of $\mathrm{Q}_{1}$ as $1_{\mathrm{u}}$ and store corresponding $\delta_{1}$ for $0 \leq \mathrm{u}$ $\leq 1$ length-1;

rename the states of $\mathrm{Q}_{\mathrm{r}}$ as $\mathrm{m}_{\mathrm{v}}$ and store corresponding $\delta_{\mathrm{r}}$ for $0 \leq$ $\mathrm{v} \leq \mathrm{r}$-length -1 ;

$\mathrm{M} \leftarrow\left(\mathrm{Q} \leftarrow\left\{\left[1_{\mathrm{u}} \mathrm{m}_{\mathrm{v}}\right] \mid 0 \leq \mathrm{u} \leq\right.\right.$ 1_length-1, $0 \leq \mathrm{v} \leq \mathrm{r}$ _length -1$\}, \Sigma$, $\left.\delta_{\text {union, }}\left[1_{0} \mathrm{~m}_{0}\right], \mathrm{F}\right)$;

$\mathrm{F} \leftarrow \phi$;

$\mathrm{u} \leftarrow 0$;

while ( $\mathrm{u} \leq 1$ llength -1$)$

begin

$\mathrm{v} \leftarrow 0$

while $(\mathrm{v} \leq \mathrm{r}$-length -1$)$

begin

$\delta_{\text {union }}\left(\left[1_{\mathrm{u}} \mathrm{m}_{\mathrm{v}}\right], \mathrm{a}\right) \leftarrow\left\{\left[1_{\mathrm{g}} \mathrm{m}_{\mathrm{h}}\right] \mid \delta_{\mathrm{l}}\left(\mathrm{l}_{\mathrm{u}}, \mathrm{a}\right)=1_{\mathrm{g}}\right.$ and $\delta_{\mathrm{r}}\left(\mathrm{m}_{\mathrm{v}}, \mathrm{a}\right)=$ $\mathrm{m}_{\mathrm{h}} \forall \mathrm{a} \in \Sigma$, and $\left.\mathrm{g}, \mathrm{h} \geq 0\right\}$;

if $1_{\mathrm{u}} \in \mathrm{F}_{1} \mathrm{OR}_{\mathrm{v}} \in \mathrm{F}_{\mathrm{r}}$ then

$\mathrm{F} \leftarrow \mathrm{F} \cup\left\{\left[1_{\mathrm{u}} \mathrm{m}_{\mathrm{v}}\right]\right\}$

endif;

$\mathrm{v} \leftarrow \mathrm{v}+1$

end;

nd;

$\mathrm{u} \leftarrow \mathrm{u}+1$

rename $\left[1_{0} \mathrm{~m}_{0}\right]$ by $\mathrm{r}_{0}$ and rename other states of $\mathrm{Q}$ as $\mathrm{r}_{\mathrm{u}}$ for $1 \leq \mathrm{u}<$ 1_length $\mathrm{x}$ r_length and also rename all these states in $\mathrm{F}$ and store corresponding $\delta_{\text {union }}$;

return $\mathrm{M} \leftarrow\left(\mathrm{Q}, \Sigma, \delta_{\text {union }}, \mathrm{r}_{0}, \mathrm{~F}\right)$;

end function;

Figure 5. Function Union obtaining union of two DFA.

Function Union joins two DFA with respect to the union operation by combining the states. Union first combines the start states of the two DFA and then makes this combined state as the start state of the resultant DFA. Let this combined state be $\left[1_{0} \mathrm{~m}_{0}\right]$, where $1_{0}$ and $\mathrm{m}_{0}$ are the start states of two inputs DFA respectively. The transition from state $\left[1_{0} \mathrm{~m}_{0}\right]$ for an alphabet symbol ' $\mathrm{a}$ ' enters into state $\left[1_{\mathrm{g}} \mathrm{m}_{\mathrm{h}}\right]$ provided that transition from state $1_{0}$ for ' $a$ ' enters into state $1_{g}$, and transition from state $m_{0}$ for ' $a$ ' enters into state $m_{h}$ in the respective DFA. Union continues this process of generating and connecting new states, by means of transitions, until it has no more new states to connect and all 
the possible transitions enter in to some state. Finally, all those combined states in this resultant DFA become final, which have any of their component states as a final state in the inputs DFA. Figure 6 shows the function Concat.

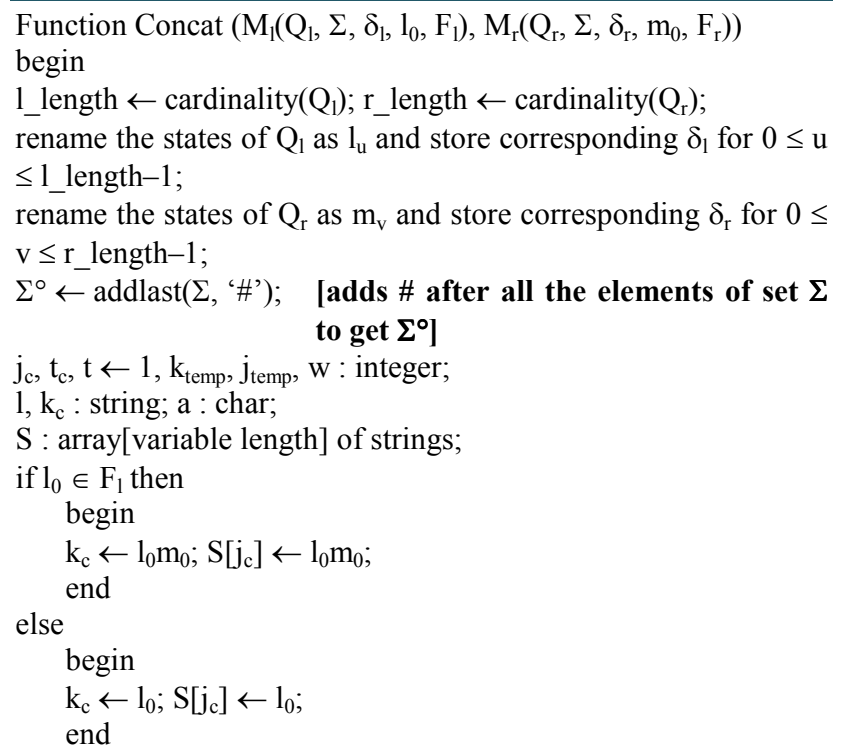

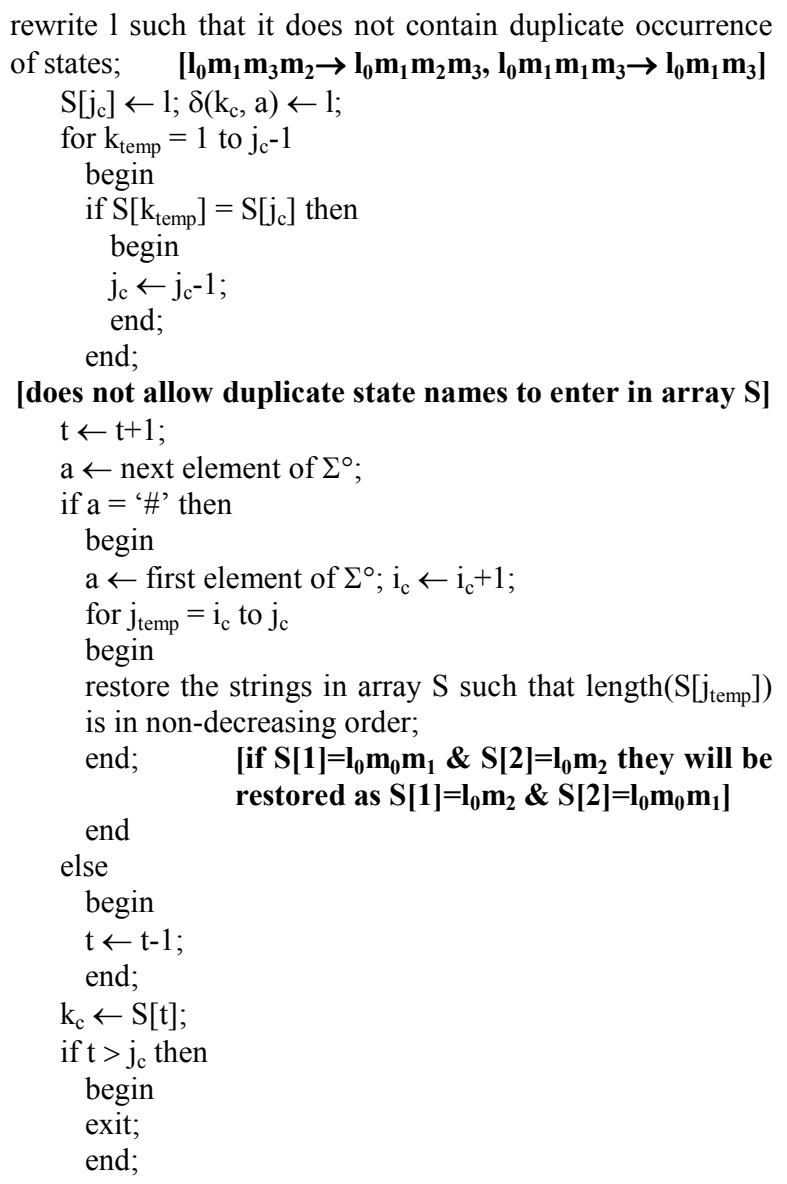

end;

$\mathrm{F} \leftarrow \phi$;

[of while $\left(\mathrm{j}_{\mathrm{c}}>\mathbf{0}\right)$ ]

\section{Figure 6. Function Concat obtaining concatenation of two} DFA.

Function Concat joins two DFA, $\mathrm{M}_{1}$ followed by $\mathrm{M}_{2}$, using the following rule. To construct $\mathrm{M}_{1} \mathrm{M}_{2}$, Concat first constructs that part of $\mathrm{M}_{1}$, which does not contain any final state of $M_{1}$. For the remaining construction, whenever Concat reaches to a final state $\mathrm{p}$ of $\mathrm{M}_{1}$, it clubs this final state $\mathrm{p}$ with the start state $\mathrm{q}$ of $\mathrm{M}_{2}$ to get a combined state [pq], and also renames state $\mathrm{p}$ as the combined state [pq]. Now Concat obtains the remaining states of $\mathrm{M}_{1} \mathrm{M}_{2}$ using the following rule. If a transition enters into a combined state [lg] for some alphabet symbol 'a', which contains any of its component states as a final state of $\mathrm{M}_{1}$, Concat clubs this combined state with the start state $\mathrm{q}$ of $\mathrm{M}_{2}$ to get a combined 
state [lgq] (new or already existing), and that transition, for the same alphabet symbol ' $a$ ', now enters into this combined state [lgq]. Then Concat constructs the remaining part of $\mathrm{M}_{1} \mathrm{M}_{2}$ using the same logic which was applied in function Union for combined states. Finally, all those combined states in $\mathrm{M}_{1} \mathrm{M}_{2}$ become final which have any of their components as a final state of $\mathrm{M}_{2}$. Figure 7 shows the function Star.

Function $\operatorname{Star}\left(\mathrm{M}\left(\mathrm{Q}, \Sigma, \delta, \mathrm{q}_{0}, \mathrm{~F}\right)\right)$

begin

length $\leftarrow$ cardinality $(\mathrm{Q})$;

rename the states of $\mathrm{Q}$ as $\mathrm{q}_{\mathrm{i}}$ and store corresponding $\delta$ for $0 \leq \mathrm{i} \leq$ length-1;

$\Sigma^{\circ} \leftarrow \operatorname{addlast}\left(\Sigma,{ }^{\prime} \#^{\prime}\right)$;

is $\leftarrow 0, \mathrm{k}$, current, $\mathrm{i}_{\text {star }}, \mathrm{t}_{\text {star }}, \mathrm{j}_{\text {star }}, \mathrm{k}_{\text {temp }}, \mathrm{j}_{\text {temp }}$, w, clos : integer;

$\mathrm{P}, \mathrm{S}, \mathrm{F}^{\prime}, \mathrm{Q}$ : array[variable length] of strings;

$\mathrm{q}, \mathrm{k}_{\text {star }}$ : string;

a : char;

$\mathrm{a} \leftarrow$ first element of $\Sigma^{\circ}$;

while $\left(\mathrm{a} \neq{ }^{\prime} \#\right.$ ')

$$
\text { begin }
$$

$$
\begin{aligned}
& \text { if } \delta\left(\mathrm{q}_{0}, \mathrm{a}\right)=\mathrm{q}_{0} \text { then } \\
& \text { begin } \\
& \text { is } \leftarrow \text { is }+1 ; \mathrm{P}[\text { is }] \leftarrow \mathrm{p}_{\text {is- } 1} ; \delta^{\prime}\left(\mathrm{q}_{0}, \mathrm{a}\right)=\mathrm{p}_{\text {is- }-1} \\
& \text { end; }
\end{aligned}
$$

a $\leftarrow$ next element of $\Sigma^{\circ}$;

end;

$\forall \mathrm{a} \in \Sigma$ begin

if $\delta\left(q_{0}, a\right)=q_{j}$, such that $j \neq 0$ then

begin

$\delta^{\prime}\left(\mathrm{q}_{0}, \mathrm{a}\right) \leftarrow \mathrm{q}_{\mathrm{j}}$

$\forall 0 \leq \mathrm{k} \leq$ cardinality $(\mathrm{P})-1$ begin

$$
\delta^{\prime}\left(\mathrm{p}_{\mathrm{k}}, \mathrm{a}\right) \leftarrow \mathrm{q}_{\mathrm{j}} \text {; }
$$

end

else

begin

if $\delta\left(\mathrm{q}_{0}, \mathrm{a}\right)=\mathrm{q}_{0}$ then

begin

$\forall 0 \leq \mathrm{k} \leq$ cardinality $(\mathrm{P})-1 \quad$ begin

$\delta^{\prime}\left(\mathrm{p}_{\mathrm{k}}, \mathrm{a}\right) \leftarrow \mathrm{p}_{\mathrm{k}} ;$

end;

end; end;

end; [this block creates self transition(s) at $\mathbf{p}_{\mathbf{i}}{ }^{\prime} \mathbf{s}$

$\forall \mathrm{a} \in \Sigma$ begin and other transition(s) for $q_{0}$ and $p_{i}$ 's]

for current $=1$ to cardinality $(\mathrm{Q})-1$

begin

$\delta^{\prime}\left(\mathrm{q}_{\text {current }}, \mathrm{a}\right) \leftarrow \delta\left(\mathrm{q}_{\text {current }}, \mathrm{a}\right)$;

end;

end;

[remaining transitions for states other than $q_{0}$ and $p_{i}{ }^{\prime} s$ ] append the states of $P$ and $Q$, after renaming $p_{i}$ 's into $q_{j}$ 's where $i$ $\geq 0$ and $\mathrm{j}=$ cardinality $(\mathrm{Q})+\mathrm{i}$ and restore $\delta$ ' for these qj's;

[adds states to DFA if there is a transition from $q_{0}$ to $q_{0}$ ]

$\mathrm{i}_{\text {star }}, \mathrm{t}_{\text {star }}, \mathrm{j}_{\text {star }} \leftarrow 1 ; \mathrm{k}_{\text {star }} \leftarrow \mathrm{q}_{0} ; \mathrm{S}\left[\mathrm{j}_{\text {star }}\right] \leftarrow \mathrm{q}_{0}$;

a $\leftarrow$ first element of $\Sigma^{\circ}$;

while $\left(\mathrm{j}_{\mathrm{star}}>0\right)$

begin

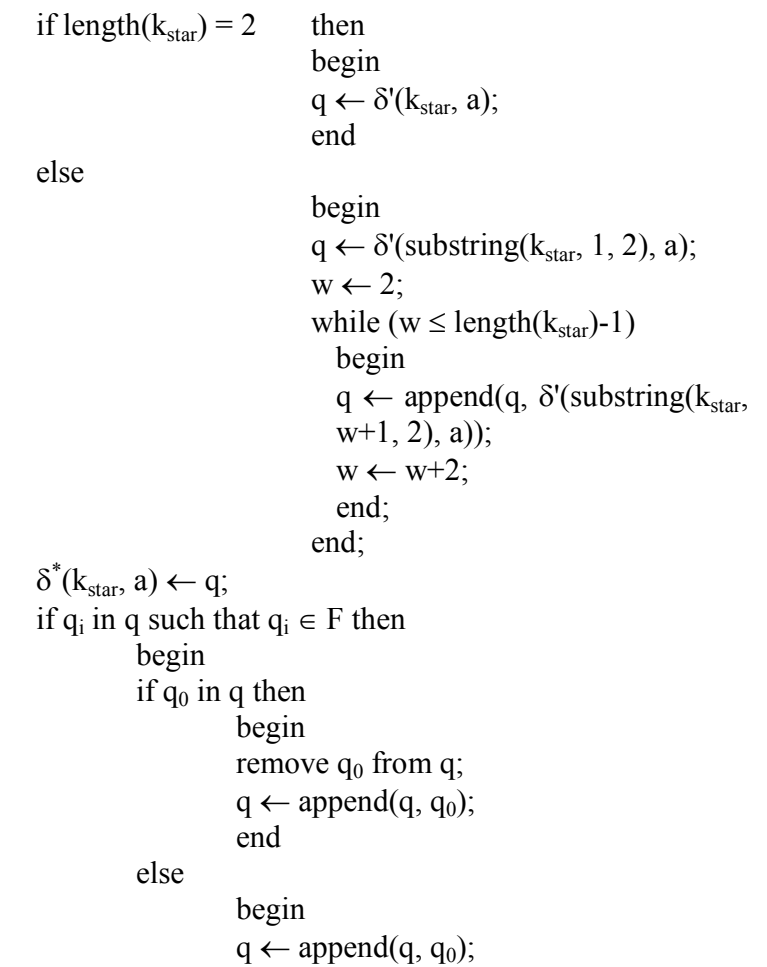

[append $q_{0}$ at the end of $q$ if $q$ contains a final state of $F$ ] end;

end;

$\mathrm{j}_{\text {star }} \leftarrow \mathrm{j}_{\text {star }}+1 ; \delta^{*}\left(\mathrm{k}_{\text {star }}, \mathrm{a}\right) \leftarrow \mathrm{q} ; \mathrm{S}\left[\mathrm{j}_{\text {star }}\right] \leftarrow \mathrm{q} ;$

rewrite $\mathrm{q}$ such that suffixes of states are in nondecreasing order;

$\left[q_{0} q_{1} q_{3} q_{2} \rightarrow q_{0} q_{1} q_{2} q_{3}\right]$

rewrite $\mathrm{q}$ such that it does not contain duplicate occurrence of states;

$\left[q_{0} q_{1} q_{1} q_{3} \rightarrow q_{0} q_{1} q_{3}\right]$

$\delta^{*}\left(\mathrm{k}_{\mathrm{star}}, \mathrm{a}\right) \leftarrow \mathrm{q}$;

$\mathrm{S}\left[\mathrm{j}_{\text {star }}\right] \leftarrow \mathrm{q}$;

for $\mathrm{k}_{\text {temp }}=1$ to $\mathrm{j}_{\text {star }}-1$

begin

if $\mathrm{S}\left[\mathrm{k}_{\text {temp }}\right]=\mathrm{S}\left[\mathrm{j}_{\text {star }}\right]$ then

begin

$\mathrm{j}_{\text {star }} \leftarrow \mathrm{j}_{\text {star }}-1$

end;

[does not allow duplicate state names to enter in array $\mathrm{S}$ ] $t_{\text {star }} \leftarrow t_{\text {star }}+1$;

a $\leftarrow$ next element of $\Sigma^{\circ}$;

if $\mathrm{a}=$ '\#' then

begin

a $\leftarrow$ first element of $\Sigma^{\circ}$;

$i_{\text {star }} \leftarrow i_{\text {star }}+1$

for $\mathrm{j}_{\text {temp }}=\mathrm{i}_{\text {star }}$ to $\mathrm{j}_{\text {star }}$

begin

restore the strings in array $\mathrm{S}$ such that length $\left(\mathrm{S}\left[\mathrm{j}_{\text {temp }}\right]\right)$ is in non-decreasing order;

[if $S[1]=q_{0} q_{2} \& S[2]=q_{1}$, they will be restored as $\left.S[1]=q_{1} \& S[2]=q_{0} q_{2}\right]$

end end;

else

begin

$\mathrm{t}_{\text {star }} \leftarrow \mathrm{t}_{\text {star }}-1$; 


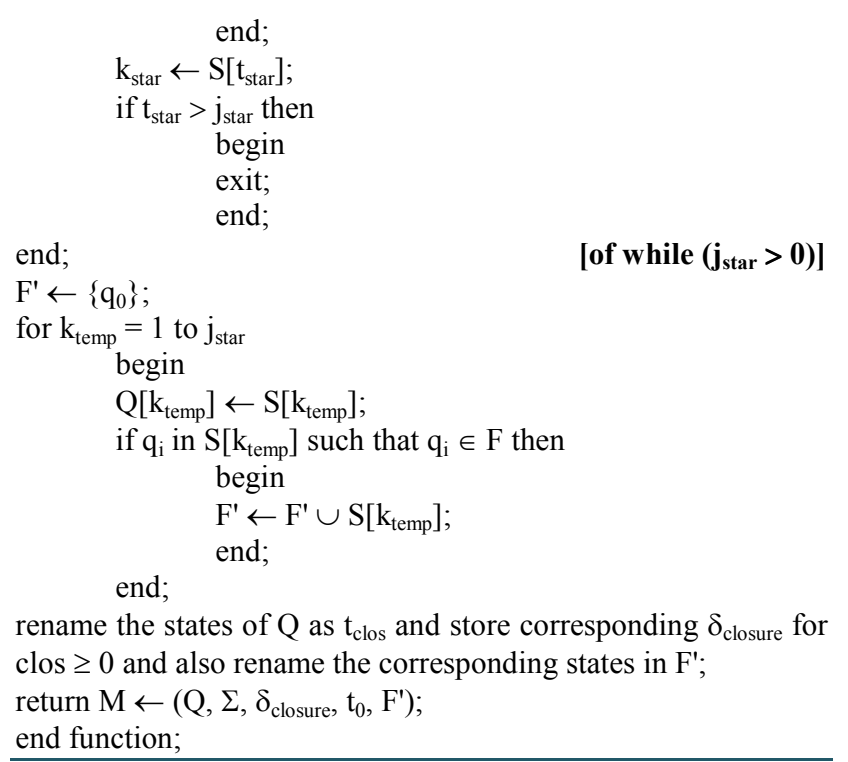

Figure 7. Function Star obtaining kleene closure of a DFA.

Function Star finds the kleene closure of a DFA M using the following rule. To construct $\mathrm{M}^{*}$, Star first checks if there is any transition from start state $\mathrm{q}_{0}$, back to $\mathrm{q}_{0}$, and if any such transition exists, then Star adds new state(s) equal to the number of such transitions. The nature (in terms of transitions) of these newly added states is same as that of the start state $\mathrm{q}_{0}$. So now Star has an intermediate DFA M', which contains no transition from start state $\mathrm{q}_{0}$, back to $\mathrm{q}_{0}$. Now to construct $\mathrm{M}^{*}$, Star first constructs that part of $\mathrm{M}^{\prime}$ which does not contain any final state. For the remaining construction of $\mathrm{M}^{*}$, whenever Star reaches to a final state $\mathrm{p}$ of $\mathrm{M}^{\prime}$, it clubs this final state with the start state q of $\mathrm{M}^{\prime}$ to get a combined state [pq] and also renames state $p$ as the combined state [pq]. Now Star obtains the remaining states of $\mathrm{M}^{*}$ using the following rule. If a transition enters into a combined state [lg] for some alphabet symbol ' $a$ ', which contains any of its components states as a final state of $\mathrm{M}^{\prime}$, Star clubs this combined state $[\mathrm{lg}]$ with the start state q of $\mathrm{M}^{\prime}$ to get a combined state [lgq] (new or already existing), and that transition, for the same alphabet symbol 'a', now enters into this combined state. Then Star constructs the remaining part of $\mathrm{M}^{*}$ using the same logic as was applied in function Union for combined states. All those combined states in $\mathrm{M}^{*}$ become final which have any of their component as a final state of $\mathrm{M}^{\prime}$. Finally in $\mathrm{M}^{*}$, Star converts the start state $\mathrm{q}_{0}$ also to a final state. Figure 8 shows the function Min.

Function $\operatorname{Min}\left(\mathrm{M}\left(\mathrm{Q}, \Sigma, \delta, \mathrm{q}_{0}, \mathrm{~F}\right)\right)$

begin

$\Sigma^{\circ} \leftarrow \operatorname{addlast}(\Sigma$, '\#');

$\mathrm{k}_{\min }$, temp, temp ${ }_{1}$, temp $2:$ integer;

$\mathrm{S}, \mathrm{F}^{\prime}$ : array[variable length] of strings;

find the equivalent states in set $\mathrm{Q}$ and store them as combined states;

store all the states (combined as well as single) of Q in array $\mathrm{S}$ such that all the component states of $\mathrm{S}\left[\mathrm{k}_{\min }\right]$ are equivalent for $\mathrm{k}$ $\geq 1$, and set $\mathrm{S}[1]$ such that it contains $\mathrm{q}_{0}$ as one of its component; $\mathrm{a} \leftarrow$ first element of $\Sigma^{\circ}$;

while $\left(\mathrm{a} \neq{ }^{\prime} \#\right.$ ')

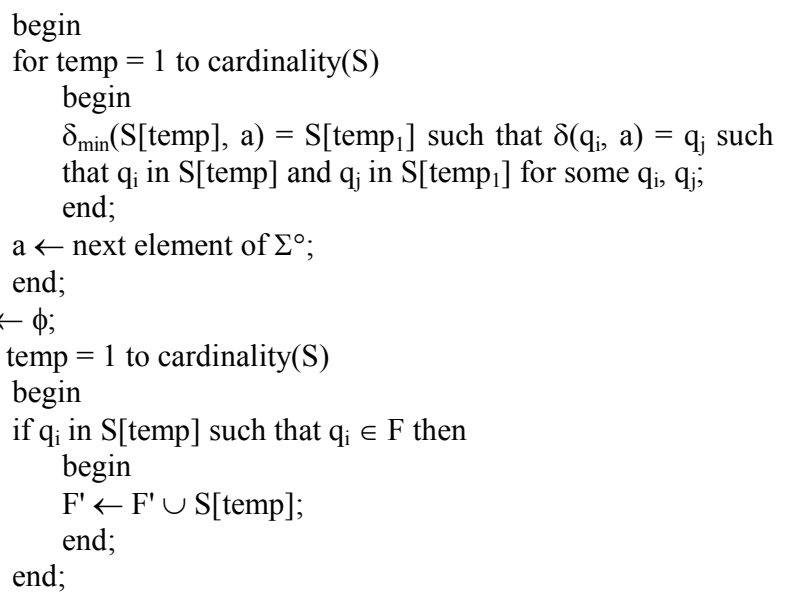
rename the states of $\mathrm{S}$ as $\mathrm{m}_{\text {temp2 }}$ and store corresponding $\delta_{\min }$ for $0 \leq$ temp $2 \leq$ cardinality(S)-1 and also rename the corresponding states in $\mathrm{F}^{\prime}$;

return $\mathrm{M} \leftarrow\left(\mathrm{S}, \Sigma, \delta_{\min }, \mathrm{m}_{0}, \mathrm{~F}^{\prime}\right)$;

end function;

Figure 8. Function Min obtaining minimal DFA equivalent to the given DFA.

Function Min converts a DFA $M$ into an equivalent DFA with minimum number of states. Min first finds the equivalent states of $\mathrm{M}$, and then clubs those equivalent states to make some combined states (Hopcroft and Ullman, [19]). All those states which are not equivalent to any other state do not form any combined state and hence, will be written as single states. Therefore now Min has, possibly, some combined states and some single states for minimal DFA $\mathrm{M}_{\min }$. The start state of the resultant DFA $\mathrm{M}_{\min }$ is either the start state $\mathrm{q}_{0}$ of $\mathrm{M}$ (if $q_{0}$ is not equivalent to any other state) or a combined state containing $\mathrm{q}_{0}$ as one of its component. Now, Min connects the start state of $\mathrm{M}_{\min }$ to some other state (combined or single) by means of transitions for all alphabet symbols, using the transitions of M. Min continues for connecting the other states also by means of transitions for all alphabet symbols. Finally, all those states (combined or single) in $\mathrm{M}_{\min }$ become final if they have anything common with the set of final states $\mathrm{F}$ of $\mathrm{M}$.

\subsection{Algorithm Implementation}

A detailed demonstration on how the algorithm Construct works is shown as successive instances of the algorithm's implementation using two different representations: firstly by graphs and secondly by tables.

\subsubsection{Using Graphs}

To convert a randomly chosen regular expression $01^{*}$ into a minimal DFA M, Construct first places $01^{*}$ in a set of parenthesis; therefore, the input will look like $\left(01^{*}\right)$. Then Construct scans for the innermost parenthesis and since, in this case only one parenthesis exists, the same is the innermost. Thereby, $1^{*}$ is the substring of regular expression for which Construct draws an initial DFA $\mathrm{L}_{1}$. Construct constructs $\mathrm{L}_{1}$ using the function $\operatorname{Min}(\operatorname{Star}(\operatorname{Symbol}(1)))$ and the successive steps of this construction are as shown by Figures $9-11$. 


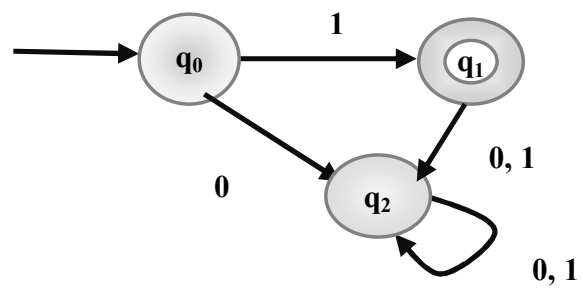

$K_{1}=\left(\left\{q_{0}, q_{1}, q_{2}\right\},\{0,1\}, \delta, q_{0},\left\{q_{1}\right\}\right)$

Figure 9. DFA $K_{1}$ designed using Symbol(1).

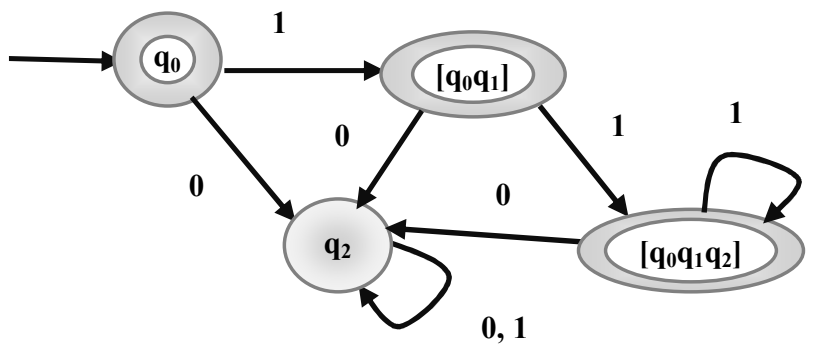

$K_{2}=\left(\left\{q_{0},\left[q_{0} q_{1}\right],\left[q_{0} q_{1} q_{2}\right], q_{2}\right\},\{0,1\}, \delta, q_{0},\left\{q_{0},\left[q_{0} q_{1}\right],\left[q_{0} q_{1} q_{2}\right]\right\}\right)$

Figure 10. DFA K $K_{2}$ designed using Star(Symbol(1)).

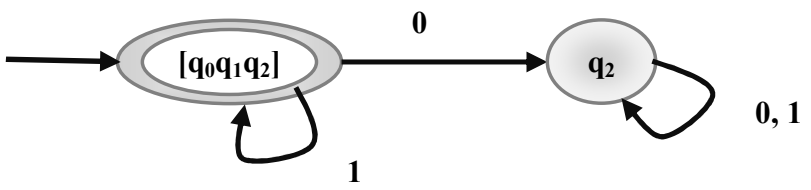

$K_{3}=\left(\left\{\left[\mathbf{q}_{0} \mathbf{q}_{1} \mathbf{q}_{2}\right], \mathbf{q}_{2}\right\},\{\mathbf{0}, \mathbf{1}\}, \delta,\left[\mathbf{q}_{0} \mathbf{q}_{1} \mathbf{q}_{2}\right],\left\{\left[\mathbf{q}_{0} \mathbf{q}_{1} \mathbf{q}_{2}\right]\right\}\right)$

Figure 11. DFA K $K_{3}$ designed using $\operatorname{Min}(\operatorname{Star}(\operatorname{Symbol}(1)))$.

Construct still runs in the same parenthesis and finds a DFA $\mathrm{N}_{1}$ equivalent to $0 \mathrm{~L}_{1}$ (value of $\mathrm{K}_{3}$ is stored in $\mathrm{L}_{1}$ ) using the following sequential construction steps (Figure 12 - 13).

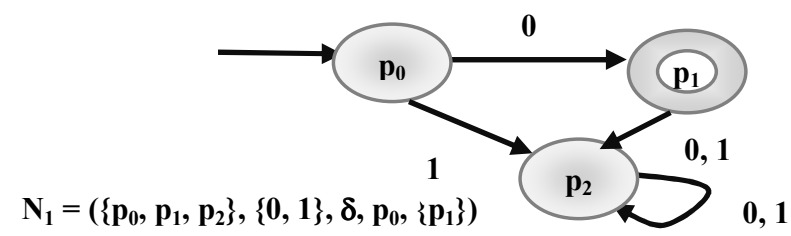

Figure 12. DFA $\mathrm{N}_{1}$ designed using Symbol(0).

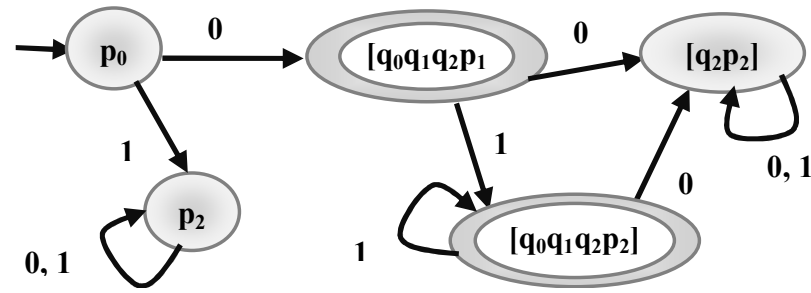

$\mathbf{N}_{1}=\left(\left\{\mathbf{p}_{0}, \mathbf{p}_{2},\left[\mathbf{q}_{2} \mathbf{p}_{2}\right],\left[\mathbf{q}_{0} \mathbf{q}_{1} \mathbf{q}_{2} \mathbf{p}_{1}\right],\left[\mathbf{q}_{0} \mathbf{q}_{1} \mathbf{q}_{2} \mathbf{p}_{2}\right]\right\},\{0,1\}, \delta, \mathbf{p}_{0}\right.$, $\left.\left\{\left[q_{0} q_{1} q_{2} p_{1}\right],\left[q_{0} q_{1} q_{2} p_{2}\right]\right\}\right)$

Figure 13. DFA $N_{1}$ designed for $N_{1} L_{1}$.
Finally, Construct minimizes the obtained DFA $\mathrm{N}_{1}$ to get minimal DFA $\mathrm{N}_{1}$ as shown in Figure 14.

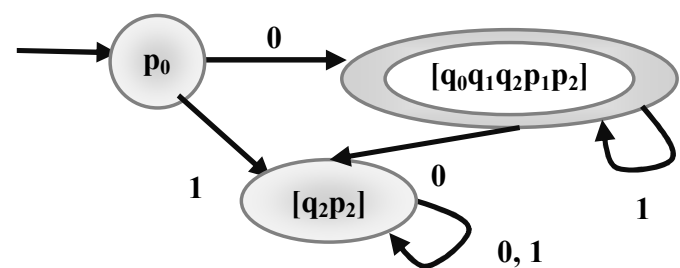

$\mathbf{N}_{1}=\left(\left\{\mathbf{p}_{0},\left[\mathbf{q}_{2} \mathbf{p}_{2}\right],\left[\mathbf{q}_{0} \mathbf{q}_{1} \mathbf{q}_{2} \mathbf{p}_{1} \mathbf{p}_{2}\right]\right\},\{0,1\}, \delta, \mathbf{p}_{0},\left\{\left[\mathbf{q}_{0} \mathbf{q}_{1} \mathbf{q}_{2} \mathbf{p}_{1} \mathbf{p}_{2}\right]\right\}\right)$

Figure 14. DFA $\mathrm{N}_{1}$ designed for its minimal version.

Therefore, the regular expression string looks like $\left(\mathrm{N}_{1}\right)$. Then Construct stores $\mathrm{N}_{1}$ as $\mathrm{M}_{1}$ and the string will look like $\left(\mathrm{M}_{1}\right)$. Finally, Construct replaces $\left(\mathrm{M}_{1}\right)$ by $\mathrm{M}_{1}$, which is the minimal DFA for the given regular expression.

In the next section, we'll present the successive instances of our algorithm's implementation over another random regular expression using table representation.

\subsubsection{Using Tables}

In this section, the algorithm Construct is applied for converting a randomly chosen regular expression $\left((0+1(01 *+0 *) * 1+1)^{*}\right)$ into a minimal DFA. Here $\mathrm{n}=20$, so Construct initializes an array X of size $22(20+2)$. Next, it places the regular expression into $X$ from $2^{\text {nd }}$ to $21^{\text {st }}$ place and also assigns $\mathrm{X}[1]={ }^{\prime}\left('\right.$ and $\left.\mathrm{X}[22]={ }^{\prime}\right)$ ' as shown in table 1. The successive instances of the algorithm's implementation are shown by the following sequence of stages of $\mathrm{X}$ in table 1 .

Table 1. Array $X$ showing the successive instances of conversion process of $((0+1(01 *+0 *) * 1+1) *)$ into DFA $M_{4}$.

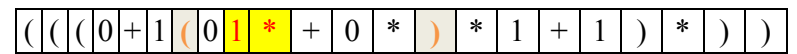

12345678910111213141516171819202122

The innermost parenthesis is from $7^{\text {th }}$ to $14^{\text {th }}$ positions, and inside this parenthesis first star is at $10^{\text {th }}$ position, and the character at (10-1) i.e. $9^{\text {th }}$ position is a 1 . So Construct replaces $9^{\text {th }}$ position by $\mathrm{L}_{1}$ (the min. DFA for $1^{*}$ ), shifts all the cell's content from $11^{\text {th }}$ position onwards to 1 position left, and finally replaces the $22^{\text {nd }}$ position by \#; next stage of $X$ is

\begin{tabular}{|l|l|l|l|l|l|l|l|l|l|l|l|l|l|l|l|l|l|l|l|}
\hline$(()($ & 0 & + & 1 & ( & 0 & $\mathrm{~L}_{1}$ & + & 0 & $*$ & ) & $*$ & 1 & + & 1 & ) & $*$ & ) & ) & $\#$ \\
\hline
\end{tabular}

12345678910111213141516171819202122

Still in the same innermost parenthesis, which is now from $7^{\text {th }}$ to $13^{\text {th }}$ positions, one more $*$ exists at position 12 . So Construct replaces $11^{\text {th }}$ position by $\mathrm{L}_{2}$ (the min. DFA for $0^{*}$ ), shifts all the cell's content from $13^{\text {th }}$ position onwards to 1 position left, and finally replaces the $22^{\text {nd }}$ position by \#; next stage of $\mathrm{X}$ is

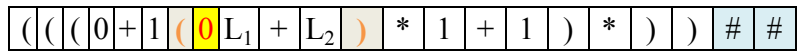

12345678910111213141516171819202122

Construct still runs in the same innermost parenthesis, which is now from $7^{\text {th }}$ to $12^{\text {th }}$ position. It reads the character at $8^{\text {th }}$ position and replaces it by $\mathrm{N}_{1}$ (the min. DFA for 0 ); next stage of $\mathrm{X}$ is 
ARRAY X (Contd.)

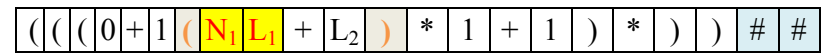

123456789910111213141516171819202122

In the same innermost parenthesis, i.e. from $7^{\text {th }}$ to $12^{\text {th }}$ positions, Construct finds a concatenation between $8^{\text {th }}$ and $9^{\text {th }}$ position. So it replaces the $8^{\text {th }}$ position by $\mathrm{N}_{1}$ (the min. DFA of concatenation of previous value stored in $\mathrm{N}_{1}$ by $\mathrm{L}_{1}$ ), shifts all the cell's content from $10^{\text {th }}$ position onwards to 1 position left, and finally replaces the $22^{\text {nd }}$ position by \#; next stage of $X$ is

\begin{tabular}{|l|l|l|l|l|l|l|l|l|l|l|l|l|l|l|l|l|}
\hline$(\mid(|0|+\mid$ & 1 & $\left(\left|\mathrm{~N}_{1}\right|+\mid \mathrm{L}_{2}\right.$ & ) & $*$ & 1 & + & 1 & ) & $*$ & ) & ) & $\#$ & $\#$ & $\#$ \\
\hline
\end{tabular}

12345678910111213141516171819202122

In the same innermost parenthesis, i.e. from $7^{\text {th }}$ to $11^{\text {th }}$ positions, Construct reads a + followed by $\mathrm{L}_{2}$, which is at $10^{\text {th }}$ position. So it replaces $10^{\text {th }}$ position by $\mathrm{N}_{2}$; next stage of $\mathrm{X}$ is

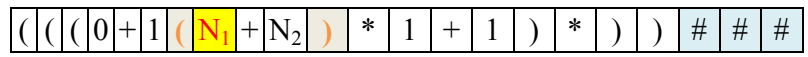

12345678910111213141516171819202122

All the possible concatenation operations are performed inside the innermost parenthesis, so now Construct checks the innermost parenthesis for the union operation. In the same innermost parenthesis, i.e. from $7^{\text {th }}$ to $11^{\text {th }}$ positions, it reads the character at $8^{\text {th }}$ position and replaces it by $M_{1}$ (the DFA $N_{1}$ is stored as name $\mathrm{M}_{1}$ ); next stage of $\mathrm{X}$ is

\begin{tabular}{|l|l|l|l|l|l|l|l|l|l|l|l|l|l|l|l|l|}
\hline$(|(\mid)|+\mid$ & $\left(\left|\mathrm{M}_{1}\right|+\left|\mathrm{N}_{2}\right|\right.$ & $*$ & $*$ & 1 & + & 1 & ) & $*$ & ) & ) & $\#$ & $\#$ & $\#$ \\
\hline
\end{tabular}

12345678910111213141516171819202122

In the same innermost parenthesis, i.e. from $7^{\text {th }}$ to $11^{\text {th }}$ positions, Construct finds a union between $8^{\text {th }}$ and $10^{\text {th }}$ position. So it replaces the $8^{\text {th }}$ position by $\mathrm{M}_{1}$ (the min. DFA of union of previous value stored in $M_{1}$ by $N_{2}$ ), shifts all the cell's content from $11^{\text {th }}$ position onwards to 2 positions left, and finally replaces each of $21^{\text {st }}$ and $22^{\text {nd }}$ positions by \#; next stage of $\mathrm{X}$ is

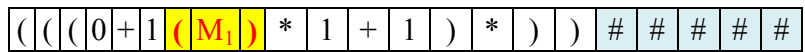

123456789610111213141516171819202122

In the same innermost parenthesis, i.e. from $7^{\text {th }}$ to $9^{\text {th }}$ positions, Construct reads a ')' at $9^{\text {th }}$ position. So it removes that innermost parenthesis, by first shifting $8^{\text {th }}$ position onwards to 1 position left, and then shifting $9^{\text {th }}$ position onwards to 1 position left, and each time replacing the $22^{\text {nd }}$ position by \#; next stage of $\mathrm{X}$ is

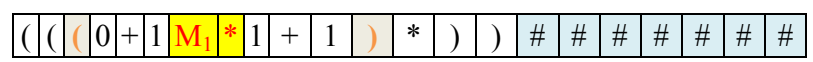

1234556788910111213141516171819202122

So now Construct has a new innermost parenthesis from $3^{\text {rd }}$ to $12^{\text {th }}$ positions. Construct scans this parenthesis for a $*$, which appears at $8^{\text {th }}$ position. It replaces the contents of $7^{\text {th }}$ position by $\mathrm{L}_{1}$ (the min DFA for $\mathrm{M}_{1}{ }^{*}$ ), shifts all the cell's content from $9^{\text {th }}$ position onwards to 1 position left, and finally replaces the $22^{\text {nd }}$ position by \#; next stage of $\mathrm{X}$ is

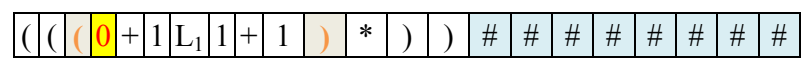

12345678910111213141516171819202122

Construct still runs in the same innermost parenthesis, which is now from $3^{\text {rd }}$ to $11^{\text {th }}$ position. It reads the character at $4^{\text {th }}$ position and replaces it by $\mathrm{N}_{1}$ (the min. DFA for 0); next stage of $\mathrm{X}$ is
ARRAY X (Contd.)

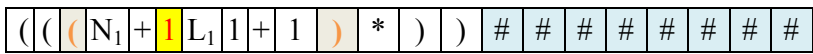

12344556789910111213141516171819202122

In the same innermost parenthesis, i.e. from $3^{\text {rd }}$ to $11^{\text {th }}$ positions, Construct reads a + followed by a 1 , which is at $6^{\text {th }}$ position. So it replaces $6^{\text {th }}$ position by $\mathrm{N}_{2}$; next stage of $\mathrm{X}$ is

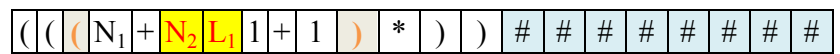

12344566789910111213141516171819202122

In the same innermost parenthesis, i.e. from $3^{\text {rd }}$ to $11^{\text {th }}$ positions, Construct finds a concatenation between $6^{\text {th }}$ and $7^{\text {th }}$ position. So it replaces the $6^{\text {th }}$ position by $\mathrm{N}_{2}$ (the min. DFA of concatenation of previous value stored in $\mathrm{N}_{2}$ by $\mathrm{L}_{1}$ ), shifts all the cell's content from $8^{\text {th }}$ position onwards to 1 position left, and finally replaces the $22^{\text {nd }}$ position by \#; next stage of $X$ is

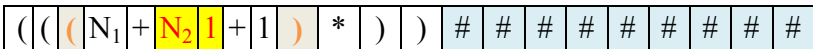

1234456678910111213141516171819202122

In the same innermost parenthesis, i.e. from $3^{\text {rd }}$ to $10^{\text {th }}$ positions, Construct finds a concatenation between $6^{\text {th }}$ and $7^{\text {th }}$ position. So it replaces the $6^{\text {th }}$ position by $\mathrm{N}_{2}$ (the min. DFA of concatenation of previous value stored in $\mathrm{N}_{2}$ by the DFA for symbol 1), shifts all the cell's content from $8^{\text {th }}$ position onwards to 1 position left, and finally replaces the $22^{\text {nd }}$ position by \#; next stage of $X$ is

\begin{tabular}{|l|l|l|l|l|l|l|l|l|l|l|l|l|l|l|l|l|l|}
\hline$\left(\mid\left(\left|\mathrm{N}_{1}\right|+\left|\mathrm{N}_{2}\right|+\mid\right.\right.$ & 1 & ) & $*$ & ) & ) & $\#$ & $\#$ & $\#$ & $\#$ & $\#$ & $\#$ & $\#$ & $\#$ & $\#$ & $\#$ \\
\hline
\end{tabular}

1234456678910111213141516171819202122

Construct still runs in the same innermost parenthesis, which is now from $3^{\text {rd }}$ to $9^{\text {th }}$ position. It reads the character at $8^{\text {th }}$ position and replaces it by $\mathrm{N}_{3}$ (the min. DFA for 1); next stage of $\mathrm{X}$ is

\begin{tabular}{|l|l|l|l|l|l|l|l|l|l|l|l|l|l|l|l|l|l|}
\hline$\left(\mid\left(\left|\mathrm{N}_{1}\right|+\left|\mathrm{N}_{2}\right|+\mathrm{N}_{3}\right.\right.$ & ) & $*$ & ) & ) & $\#$ & $\#$ & $\#$ & $\#$ & $\#$ & $\#$ & $\#$ & $\#$ & $\#$ & $\#$ \\
\hline
\end{tabular}

1234456778910111213141516171819202122

All the possible concatenation operations are performed inside the innermost parenthesis, so now Construct checks the innermost parenthesis for the union operation. In the same innermost parenthesis, i.e. from $3^{\text {rd }}$ to $9^{\text {th }}$ positions, it reads the character at $4^{\text {th }}$ position and replaces it by $\mathrm{M}_{2}$ (the DFA $\mathrm{N}_{1}$ is stored as name $\mathrm{M}_{2}$ ); next stage of $\mathrm{X}$ is

\begin{tabular}{|l|l|l|l|l|l|l|l|l|l|l|l|l|l|}
$\left(\mid\left(\left|\mathrm{M}_{2}\right|+\left|\mathrm{N}_{2}\right|+\left|\mathrm{N}_{3}\right|\right)\right.$ & $*$ & ) & ) & $\#$ & $\#$ & $\#$ & $\#$ & $\#$ & $\#$ & $\#$ & $\#$ & $\#$ & $\#$ \\
\hline
\end{tabular}

1234456678910111213141516171819202122

In the same innermost parenthesis, i.e. from $3^{\text {rd }}$ to $9^{\text {th }}$ positions, Construct finds a union between $4^{\text {th }}$ and $6^{\text {th }}$ positions. So it replaces the $4^{\text {th }}$ position by $\mathrm{M}_{2}$ (the min. DFA of union of previous value stored in $\mathrm{M}_{2}$ by $\mathrm{N}_{2}$ ), shifts all the cell's content from $7^{\text {th }}$ position onwards to 2 positions left, and finally replaces each of the $21^{\text {st }}$ and $22^{\text {nd }}$ positions by \#; next stage of $X$ is

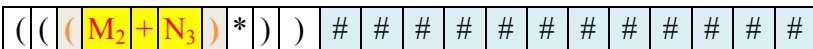

$1223 \quad 4 \quad 5 \quad 6 \quad 78910111213141516171819202122$

In the same innermost parenthesis, i.e. from $3^{\text {rd }}$ to $7^{\text {th }}$ positions, Construct finds a union between $4^{\text {th }}$ and $6^{\text {th }}$ positions. So it replaces the $4^{\text {th }}$ position by $\mathrm{M}_{2}$ (the min. DFA of union of previous value stored in $\mathrm{M}_{2}$ by $\mathrm{N}_{3}$ ), shifts all the cell's content from $7^{\text {th }}$ position onwards to 2 positions left, and finally replaces each of the $21^{\text {st }}$ and $22^{\text {nd }}$ positions by \#; next stage of $X$ is 
Table 2. Comparison Table between $n, n \cdot \log _{e} n, n \cdot \log _{2} n$ and time taken by proposed algorithm.

\begin{tabular}{|c|c|c|c|c|c|}
\hline $\mathbf{n}$ & "n" & $n \cdot \log _{e} n$ & $n \cdot \log _{2} n$ & $n^{2}$ & $\begin{array}{c}\text { Average Time } \\
\text { taken by } \\
\text { proposed } \\
\text { algorithm }\end{array}$ \\
\hline 1 & 1 & 0 & 0 & 1 & 1 \\
\hline 5 & 5 & 8.05 & 11.61 & 25 & 26.2 \\
\hline 10 & 10 & 23.03 & 33.22 & 100 & 46 \\
\hline 15 & 15 & 40.62 & 58.60 & 225 & 65.8 \\
\hline 20 & 20 & 59.92 & 86.44 & 400 & 92.4 \\
\hline 25 & 25 & 80.47 & 116.10 & 625 & 110.6 \\
\hline 30 & 30 & 102.04 & 147.21 & 900 & 127.4 \\
\hline 35 & 35 & 124.44 & 179.53 & 1225 & 148.4 \\
\hline 40 & 40 & 147.56 & 212.88 & 1600 & 167 \\
\hline 45 & 45 & 171.30 & 247.13 & 2025 & 190 \\
\hline 50 & 50 & 195.60 & 282.19 & 2500 & 221 \\
\hline 75 & 75 & 323.81 & 467.16 & 5625 & 318.6 \\
\hline 100 & 100 & 460.52 & 664.39 & 10000 & 426.4 \\
\hline 150 & 150 & 751.60 & 1084.32 & 22500 & 608.2 \\
\hline 200 & 200 & 1059.66 & 1528.77 & 40000 & 804 \\
\hline
\end{tabular}

As shown in table 2, the proposed algorithm takes a little more time than $\mathrm{n} \cdot \log _{2} \mathrm{n}$ for $1 \leq \mathrm{n} \leq 10$; it coincides with the time $\mathrm{n} . \log _{2} \mathrm{n}$ for $10 \leq \mathrm{n} \leq 20$; and then it becomes better by taking less time than $n \cdot \log _{2} n$ for $n>20$. In addition, the algorithm's time complexity becomes better than $n \cdot \log _{\mathrm{e}} n$ when $n \geq 75$. Hence, the proposed algorithm takes $\mathrm{O}\left(\mathrm{n} \cdot \log _{2} \mathrm{n}\right)$ time. Besides, for larger values of $n(n \geq 75)$ the proposed algorithm becomes more timeefficient and shows a time complexity of $\mathrm{O}\left(\mathrm{n} \cdot \log _{\mathrm{e}} n\right)$ as shown in figure 15.

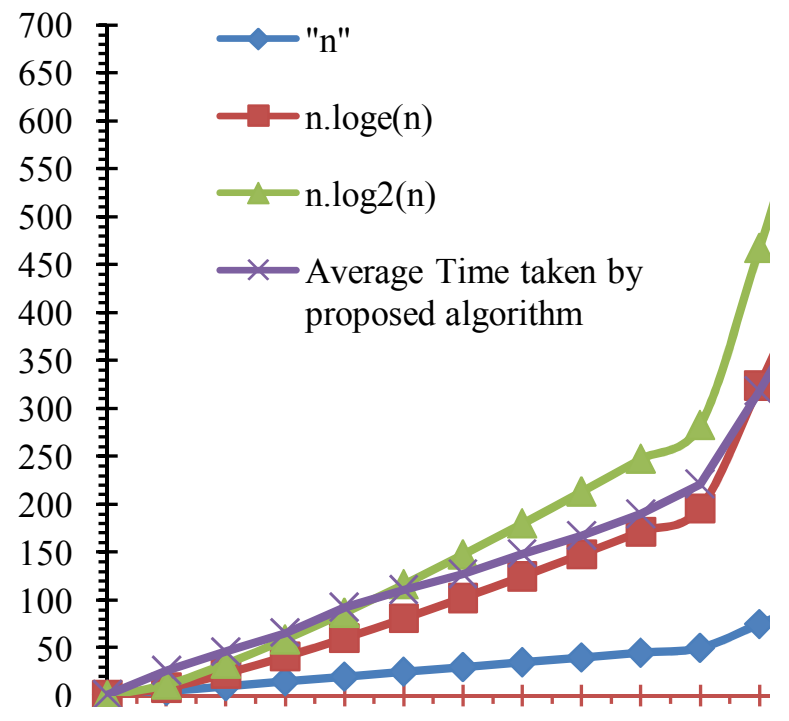

Figure 15. Comparison Graph between $n, n \cdot \log _{e} n, n \cdot \log _{2} n$ and time taken by proposed algorithm.

\section{CONCLUSION AND FUTURE WORK}

From the basic results of formal language parsing, graph grammars and automata theory we have derived a simple novel method to construct a minimal deterministic finite automaton from a regular expression. We have applied our method to a lot of regular expressions and obtained the desired and exact results all the times showing thereby the applicability of our method for getting the minimal DFA from a regular expression. This method removes the dependency over the necessity of lengthy chain of conversion, that is, regular expression $\rightarrow$ NFA with $\varepsilon$ transitions $\rightarrow$ NFA without $\varepsilon$-transitions $\rightarrow$ DFA $\rightarrow$ minimal DFA. Therefore the main advantages of our minimal DFA construction algorithm are its minimal intermediate memory requirements and hence, it's reduced time complexity. This algorithm converts a regular expression of size $\mathrm{n}$ in to its minimal equivalent DFA in $\mathrm{O}\left(\mathrm{n} \cdot \log _{2} \mathrm{n}\right)$ time. In addition to this, the time complexity is further shortened to $O\left(n \cdot \log _{e} n\right)$ for $n \geq 75$.

Glushkov [14] presented a method to convert a regular expression into an $\varepsilon$-free NFA with $\mathrm{O}\left(\mathrm{n}^{2}\right)$ transitions while Hagenah and Muscholl [17] performed the same conversion with $\mathrm{O}\left(\mathrm{n} \cdot \log ^{2}(\mathrm{n})\right)$ transitions. Later, Hromkovic et al. [20] gave a method for the above conversion where the time complexity was $\mathrm{O}\left(\mathrm{n} \cdot \log _{2} \mathrm{n}\right)$ which was the least amongst all the above methods. However, all the above methods were inadequate as they converted a regular expression into only an $\varepsilon$-free NFA and not into minimal DFA. Therefore, additional time was required to convert $\varepsilon$-free NFA into minimal DFA. Hence, the overall time complexity for the required conversion was more than $\mathrm{O}\left(\mathrm{n} \cdot \log _{2} \mathrm{n}\right)$. However, our method converted a regular expression into a minimal DFA directly in $\mathrm{O}\left(\mathrm{n} \cdot \log _{2} \mathrm{n}\right)$ time hence, showing the supremacy of our method over the above methods.

Furthermore, Rytter [28] presented a method for converting a regular expression of size $\mathrm{n}$ into an NFA in $\log n$ time using $(n / \log n)$ parallel processors. As compared to Rytter's method [28], our method converted a regular expression of size $n$ into a DFA in $\mathrm{O}\left(\mathrm{n} \cdot \log _{2} \mathrm{n}\right)$ steps using a high-speed processor. Thereby, the number of processors was reduced to 1 by our method. However, the time complexities were not comparable as the two methods produced different outputs; Rytter's method [28] produced NFA while our method produced minimal DFA. Hence, results by our algorithm are an improvement over Rytter's method [28].

Most researches attempted hitherto are based on the use of intermediate NFA for the above conversion. However, the present algorithm uses intermediate DFA in place of NFA, and still shows a time complexity which is shorter as compared to other available methods, thus motivating the use of DFA in place of NFA for similar studies. In addition to this, the above algorithm also inspires a further study for producing a more time-efficient algorithm for the above conversion.

\section{REFERENCES}

[1] Antimirov, V. [1996]. "Partial derivatives of regular expressions and finite automata constructions". Theoretical Computer Science. vol. 155, no. 2, pp. 291-319.

[2] Ben-David, S., D. Fisman, and S. Ruah [2008]. "Embedding finite automata within regular expressions". Theoretical Computer Science. vol. 404, no. 3, pp. 202218.

[3] Berry, G. and R. Sethi [1986]. "From regular expressions to deterministic automata". Theoretical Computer Science. vol. 48, no. 1, pp. 117-126.

[4] Berstel, J., D. Perrin, and C. Reutenauer [2009]. Codes and Automata. Encyclopedia of Mathematics and its 
Applications no. 129. Cambridge University Press. Cambridge.

[5] Bruggemann-Klein A. [1993]. "Regular expressions into finite automata". Theoretical Computer Science. vol. 120, no. 2, pp. 197-213.

[6] Brzozowski, J. A. and R. Cohen [1969]. "On decompositions of regular events". Journal of the ACM (J. $A C M)$. vol. 16, no. 1, pp. 132-144.

[7] Carrasco, R. C., J. Daciuk, and M. L. Forcada [2009]. "Incremental construction of minimal tree automata". Algorithmica. vol. 55, no. 1, pp. 95-110.

[8] Carrasco, R. C. and M. L. Forcada [2001]. "Incremental construction and maintenance of minimal finite-state automata”. Computational Linguistics. vol. 28, no. 2, pp. 207-216.

[9] Chang, C. H. and R. Paige [1992]. "From regular expressions to DFAs using compressed NFAs". In Proceedings of the 3rd Annual Symposium on Combinatorial Pattern Matching. Lecture notes in Computer Science no. 644. Springer-Verlag, London. pp. 90-110.

[10] Cohen, D. I. A. [1991]. Introduction to Computer Theory. 2nd edn. John Wiley \& Sons, Inc. New York.

[11] Daciuk, J., S. Mihov, B. W. Watson, and R. E. Watson [2000]. "Incremental construction of minimal acyclic finite-state automata". Computational Linguistics. vol. 26, no. 1 , pp. 3-16.

[12] Geffert, V. [2003]. "Translation of binary regular expressions into nondeterministic $\varepsilon$-free automata with o(nlogn) transitions". Journal of Computer and System Sciences. vol. 66, no. 3, pp. 451-472.

[13] Ginzburg, A. [1968]. Algebraic Theory of Automata. Academic Press. New York.

[14] Glushkov, V. M. [1961]. "The abstract theory of automata". Uspekhi Mathematicheskikh Nauk (UMN). vol. 16 , no. 5(101), pp. 3-62.

[15] Greenlaw, R. and H. Hoover [1998]. Fundamentals of the Theory of Computation: Principles and Practice. Morgan Kaufmann Publishers, Inc. Elsevier, San Francisco, USA.

[16] Gurari, E. [1989]. An Introduction to the Theory of Computation. Computer Science Press. Ohio State University, Columbus, Ohio.

[17] Hagenah, C. and A. Muscholl [1998]. "Computing epsilonfree NFA from regular expressions in o(n. $\left.\log ^{2}(\mathrm{n})\right)$ time". In Proceedings of the 23rd International Symposium on Mathematical Foundations of Computer Science. Lecture Notes in Computer Science no. 1450. Springer-Verlag, London. pp. 277-285.

[18] Hein, J. L. [1996]. Theory of Computation. Jones \& Bartlett Publishers, Inc. Sudbury, MA.

[19] Hopcroft, J. E. and J. Ullman [1979]. Introduction to Automata Theory, Languages and Computation. AddisonWesley Longman Publishing Company, Inc. Boston, MA, USA.

[20] Hromkovic J., S. Seibert, and T. Wilke [2001]. "Translating regular expressions into small $\varepsilon$-free nondeterministic finite automata". Journal of Computer and System Sciences. vol. 62, no. 4, pp. 565-588.

[21] Ilie L. and S. Yu [2003]. "Follow automata". Information and Computation. vol. 186, no. 1, pp. 140-162.

[22] Johnson, W. L., J. H. Porter, S. I. Ackley, and D. T. Ross [1968]. "Automatic generation of efficient lexical processors using finite state techniques". Communications of the ACM. vol. 11, no. 12, pp. 805-813.

[23] Leiss, E. [1980]. "Constructing a finite automaton for a given regular expression". ACM Special Interest Group on Algorithms and Computation Theory (ACM SIGACT News). vol. 12, no. 3, pp. 81-87.

[24] Lewis, H. R. and C. H. Papadimitriou [2001]. Elements of the Theory of Computation. 2nd edn. Pearson Education Asia. Delhi.

[25] Martin, J. [2004]. Introduction to Languages and the Theory of Computation. 3rd edn. Tata McGraw Hill. New Delhi.

[26] Mayr, Ernst W., G. Schmidt, and G. Tinhofer (eds.) [1995]. Graph-Theoretic Concepts in Computer Science. Lecture notes in Computer Science no. 903. SpringerVerlag, Berlin/Heidelberg, New York.

[27] Möhring, R. H. (ed.) [1991]. Graph-Theoretic Concepts in Computer Science, 16th International Workshop, WG '90, Berlin, Germany, June 20-22, 1990, Proceedings. Lecture Notes in Computer Science no. 484. Springer. London, UK.

[28] Rytter, W. [1989]. "A note on optimal parallel transformations of regular expressions to nondeterministic finite automata". Information Processing Letters. vol. 31, no. 2, pp. 103-109.

[29] Singh, A. [2009]. Elements of Computation Theory. Springer-Verlag. London.

[30] Sipser, M. [2006]. Introduction to the Theory of Computation. 2nd edn. PWS Publishing.

[31] Stefano, C. R. [2009]. Formal Languages and Compilation. Springer-Verlag. London.

[32] Taylor, R. G. [1998]. Models of Computation and Formal Languages. Oxford University Press. New York.

[33] Thompson, K. [1968]. "Regular expression search algorithms". Communications of the ACM. vol. 11, no. 6 , pp. 419-422.

[34] Watson, B. [1995]. "Taxonomies and toolkits of regular language algorithms". Ph.D. Thesis. Eindhoven University of Technology, CIP-DATA Koninklijke Bibliotheek, Den Haag.

[35] Wood, D. [1987]. Theory of Computation: A Primer. Addison-Wesley Longman Publishing Company, Inc. Boston, MA, USA.

[36] Yamamoto, H. [2005]. "New finite automata corresponding to semiextended regular expressions". Systems and Computers in Japan. vol. 36, no. 10, pp. 54-61.

[37] Ziadi, D. and J. M. Champarnaud [1999]. "An optimal parallel algorithm to convert a regular expression into its Glushkov automaton". Laboratoire d'Informatique de Rouen. vol. 215, no. 1-2, pp. 69-87. 